\title{
Chasing fish and catching data: recreational spearfishing videos as a tool for assessing the structure of fish assemblages on shallow rocky reefs
}

\author{
Fabio Bulleri*, Lisandro Benedetti-Cecchi \\ Dipartimento di Biologia, Università di Pisa, Via Derna 1, Pisa 56126, Italy
}

\begin{abstract}
Several citizen science initiatives, taking advantage of growing numbers of recreational SCUBA divers, have produced information for conserving marine biodiversity. In contrast, the potential benefits of involving recreational spearfishers in research activities has been utterly overlooked. A noteworthy aspect of modern breath-holding spearfishing is the use of full HD microcameras for recording the fishing action. When using the sit and wait fishing technique, the spearfisher remains still on the bottom, waiting for the prey to approach. These videos may provide information on fish species richness and relative abundances. We explored the potential of recreational spearfishing footage for assessing the structure of fish assemblages on shallow rocky reefs. We assessed how estimates of fish species richness, composition and relative abundance from spearfishing videos compare to those from underwater visual censuses (UVC), at 2 sites in the NW Mediterranean. Species accumulation curves show that the 2 sampling methods provided comparable estimates of species richness for any sample size. Although the structure of fish assemblages differed between UVC and videos, the relative abundance of only a few species, mostly characterized by a sedentary habit, was greater in UVC than videos. In addition, in order to show the potential use of information from spearfishing videos, we modelled the occupancy of a species (the wrasse Symphodus rostratus) at increasing distances from a commercial port, explicitly incorporating imperfect detectability as a function of video length and habitat characteristics. While the occupancy of this species did not vary with distance from the port, its detectability depended on video length. Our study suggests that videos recorded by recreational spearfishers may be useful for monitoring fish assemblages and for testing hypotheses at large spatial and temporal scales.
\end{abstract}

KEY WORDS: Citizen science $\cdot$ Fish assemblages $\cdot$ Mediterranean $\cdot$ Rocky reefs $\cdot$ Spearfishing Underwater video $\cdot$ Underwater visual census

Resale or republication not permitted without written consent of the publisher

\section{INTRODUCTION}

Natural systems worldwide are threatened by compounded human perturbations operating at a hierarchy of spatial scales, from local to global (Vitousek et al. 1997). The lack of data describing patterns of species distribution across time and space is the main hurdle to achieve evidence-based conservation and management practices. In the past decade, citizen science - the involvement of citizens in both scienti- fic thinking and data collection - has emerged as a formidable research tool to address many ecological issues that, due to time and financial constraints, could be hardly tackled by means of scientific campaigns (Dickinson et al. 2010).

In marine environments, successful citizen science initiatives have been established to record species outbreaks (e.g. JellyWatch; www.jellywatch.org) or invasions (Delaney et al. 2008), survey beach litter (Rosevelt et al. 2013) and reef diversity (Francisco- 
Ramos \& Arias-González 2013; Cybelle planete: www. cybelle-planete.org/cybelle2/) or monitor charismatic fauna, such as sharks (Ward-Paige \& Lotze 2011a, Witt et al. 2012), stingrays (Ward-Paige et al. 2011b), seahorses (Goffredo et al. 2004) and red coral (Bramanti et al. 2011). Many of these initiatives have taken advantage of the growing number of recreational SCUBA divers and their positive attitude towards conservation activities. In contrast, the potential of spearfishers in contributing information useful for the conservation and management of shallow coastal systems has been utterly overlooked.

Spearfishing by breath-holding divers is an expanding recreational activity in many temperate and tropical regions, as shown by the participation of 19 national teams in the 2012 world championship (held by the Confédération Mondiale des Activités Subaquatiques; www.cmas.org/spearfishing/114-39622php, accessed 28 March 2014). In the past decade, likely as a response to the progressive decline of prey, there has been a remarkable evolution in spearfishing: improved diving gear (e.g. carbon fins and spearguns; warmer and more flexible wetsuits), greater physical/mental training and a refinement of fishing techniques. One noteworthy aspect of modern spearfishing is the widespread use of full HD microcameras for recording the fishing action, generally mounted on the speargun or strapped on the head. When using the sit-and-wait fishing technique, the diver remains still on the bottom, partially or totally hidden from the fish sight, waiting for the prey to approach. Under these circumstances, the video camera faces the same direction for several seconds and the resulting footage, although encompassing a relatively short timeframe, might provide information on species richness and relative abundances. These might be comparable, to some extent, to estimates produced by stationary point counts (Bohnsack \& Bannerot 1986) or ad hoc video sampling techniques employed for assessing the structure of fish assemblages (Willis \& Babcock 2000, Willis et al. 2000, Cappo et al. 2004, Stobart et al. 2007).

Non-destructive sampling methods like underwater visual census (UVC; strip transects or stationary points) have been proved to be an effective tool for assessing the structure of shallow-water fish assemblages and for monitoring the effectiveness of MPAs (Harmelin-Vivien et al. 1985, Bohnsack \& Bannerot 1986). The application of remotely operated video surveys has, however, increased as an attempt to solve some of the shortcomings of UVC, such as constraints in SCUBA diving activities (time, depth), variability among observers, lack of repeatability and species-specific response to the presence of a diver (Willis et al. 2000, Cappo et al. 2004, Stobart et al. 2007, Colton \& Swearer 2010). In particular, the application of baited remote underwater video stations (BRUVS) has been proven effective in recording diverse fish assemblages. Nonetheless, this methodology also has limitations, mainly resulting from difficulties in modeling the bait odour plume in respect to the sensory capacity of the different species (Heagney et al. 2007), species-specific response to the bait (Priede \& Merrett 1998) and the occurrence of competitive interactions among the species attracted to the bait (Willis et al. 2000). There is therefore mounting consensus that no single visual sampling method can be retained as universally superior to the others.

Here, we explore the potential of recreational spearfishing video for assessing the structure of fish assemblages on shallow rocky reefs. In particular, the aim of this study was assessing how estimates of species richness, composition and relative abundances of fish from spearfishing videos compare to those obtained by UVC (strip transects, a widely used method in the Mediterranean). In addition, in order to show the potential use of spearfishing videos for testing broad hypotheses, we investigated how estimates of species occupancy (i.e. probability of presence in a sampling unit) can be improved by taking into account imperfect detection (the probability of correctly recording the presence of a species when present in a sampling unit; MacKenzie et al. 2002, 2006, Katsanevakis et al. 2011, Issaris et al. 2012). In order to provide a worked example, we modelled the occupancy of a species (the wrasse Symphodus rostratus) at increasing distances from a commercial port, explicitly incorporating imperfect detectability as a function of covariates extracted from videos (video length and habitat characteristics).

\section{MATERIALS AND METHODS}

\section{Comparisons between spearfishing videos and UVC}

This study was carried out in the NW Mediterranean, along the coast between the town of Livorno $\left(43.55^{\circ} \mathrm{N}, 10.32^{\circ} \mathrm{E}\right)$ and the rocky shore of Calafuria $\left(43.48^{\circ} \mathrm{N}, 10.33^{\circ} \mathrm{E}\right)$ (Fig. 1). Run-off and inputs of organic and inorganic pollutants along this coast are lower compared to levels recorded at Livorno (Tamburello et al. 2012), but fish assemblages are heavily exploited by a variety of recreational and commercial 


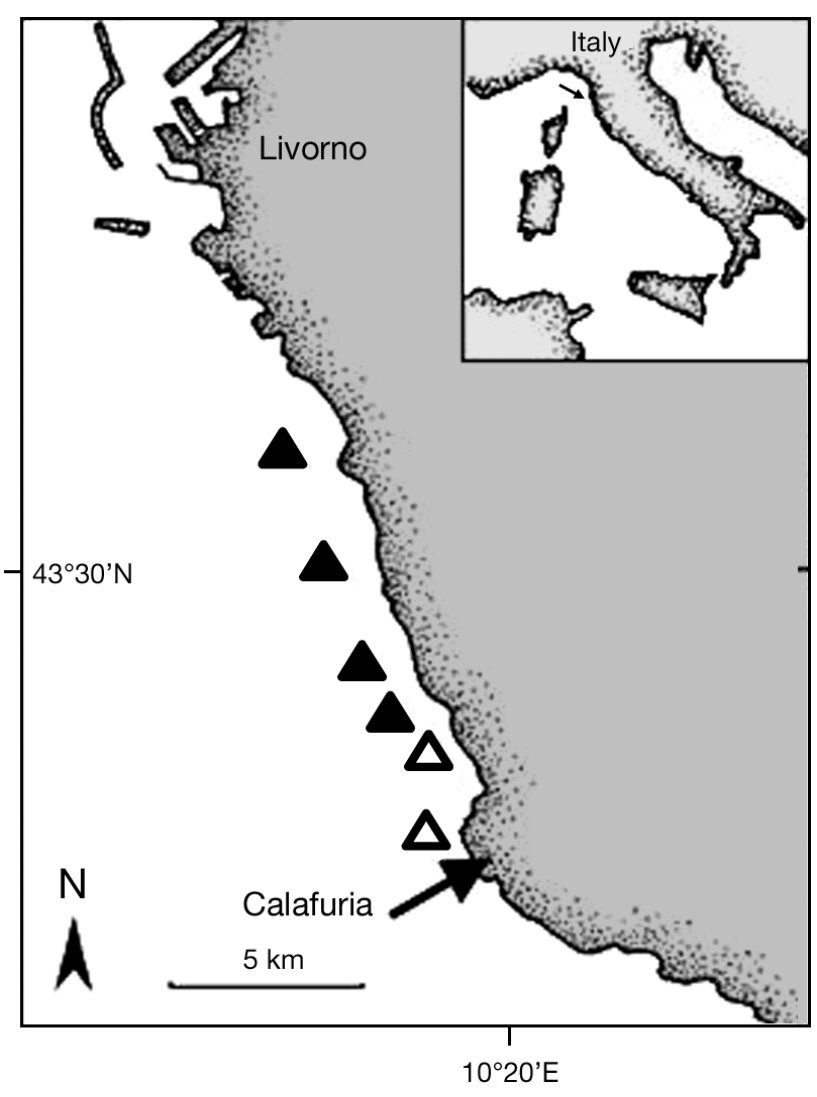

Fig. 1. Study area along the coast south of Livorno (arrow in inset indicates study area location on the Italian west coast). All 6 sites (filled and hollow triangles) were included in the modelling of Symphodus rostratus occupancy (sampled once in 2012). The 2 sites at which comparisons between UVC and spearfishing videos were made are represented by hollow triangles (Site 1 and Site 2 from north to south; each sampled 3 times in 2013, by means of both UVC and videos)

activities (authors' unpubl. data). Rocky reefs are characterized by mosaics of habitats, such as seagrass (Posidonia oceanica), coralligenous formations, turf-forming and photophilous macroalgae and encrusting coralline barrens (Tamburello et al. 2012).

Two sites $\sim 2.5 \mathrm{~km}$ apart were randomly chosen (Fig. 1). At each site, fish assemblages at a depth of 6 to $10 \mathrm{~m}$ were sampled by means of both UVC and spearfishing videos, within an area of $\sim 70000 \mathrm{~m}^{2}$ (approx. $350 \mathrm{~m}$ alongshore and $200 \mathrm{~m}$ perpendicular to shore). At each site, sampling via each of the 2 techniques was repeated at 3 randomly chosen dates, between June and October 2013. Sampling was never carried out when visibility was lower than $6 \mathrm{~m}$ and, on a given day, only 1 site was sampled and a technique employed. The same camouflage wetsuit and fins were used for all sampling events, plus a black buoyancy jacket and regulators when SCUBA diving.
Visual censuses were done along $25 \times 4 \mathrm{~m}$ transects while SCUBA diving, a common method for sampling shallow rocky reef assemblages in the Mediterranean (Harmelin-Vivien et al. 1985, Guidetti 2006). For each sampling time, fish assemblages were censused along 6 transects $\sim 100 \mathrm{~m}$ apart, (except for 1 occasion at Site 2 , in which 8 transects were censused). Videos were recorded while spearfishing (i.e. breath-holding diving), using a full HD microcamera (Go-Pro Hero $\left.{ }^{\circledR}\right)$, equipped with a flat lens, mounted on the left side of a $1 \mathrm{~m}$ long speargun, recording footage with an angle of $\sim 80^{\circ}$. For each fishing session, 15 to 23 dives (approx. $25 \mathrm{~m}$ apart) were performed across the study area, which is consistent with a typical 2 to $3 \mathrm{~h}$ spearfishing session. Footage was recorded while using the sit-and-wait fishing technique. This technique exploits the natural behaviour of predatory fish to check out potential food sources; it implies the spearfisher will remain still on the bottom, waiting for the prey to approach, while taking advantage of habitat features (e.g. boulders, outcrops, seagrass leaves) to hide, partially or totally, from the sight of fish. The camera was switched on just before starting a dive and switched off when the surface was reached. In order to mimic actual spearfishing, duration of dives was not standardized.

Each video was analyzed on a standard computer and footage that was not performed using the sitand-wait technique or of low quality was discarded. Fish counting started soon after the spearfisher had taken position on the bottom and was terminated at the end of the hunting action, corresponding to the departure from the bottom (i.e. the diver starts ascending to the surface). All counted fish were identified to the species level, except for some small individuals belonging to the genus Symphodus. Cryptic species (e.g. Gobidae and Blennidae) were not censused, since they can hardly be identified from videos and strip transects. The duration of video readings was not standardized, but varied between 18 and $60 \mathrm{~s}$, generating sampling times across a fishing session from 386 to $913 \mathrm{~s}$. During each fishing session, visibility was quantified by means of a measuring tape. It was then used to calculate the area sampled by videos, roughly estimated as the proportion of the circumference captured when filming with an $80^{\circ}$ angle. For example, a visibility of $7 \mathrm{~m}$ means the sampling area encompasses $34.2 \mathrm{~m}^{2}$; for $8 \mathrm{~m}$, $44.7 \mathrm{~m}^{2}$. Despite visibilities greater than $12 \mathrm{~m}$, Bohnsack \& Bannerot (1986) set $7.5 \mathrm{~m}$ the maximum at which small individuals could be identified in stationary point counts. Here, taking advantage of the possibility of replaying videos and using slow motion, 
the maximum distance was set at $8 \mathrm{~m}$. For each video, the maximum number of individuals of each species of fish seen together in any one time over the whole duration of the video and within the sampled area was recorded (MaxN; Priede et al. 1994, Cappo et al. 2004). MaxN has been previously found to be correlated with footage length (Ellis \& DeMartini 1995). In this study, Spearman's rank correlation indicated that there was no significant correlation between $\operatorname{Max} N$ and video length for any of the species analyzed (see Table S1 in the Supplement at www.int-res.com/articles/suppl/m506p255_supp.pdf).

In order to standardize the area sampled and enhance formal comparisons of fish species richness and relative density with transects, data from subsequent videos were pooled. The number of pooled videos necessary to cover a surface comparable to that of transects $\left(100 \mathrm{~m}^{2}\right)$ varied according to visibility: pooling 2 videos when visibility was $8 \mathrm{~m}$ generated a total sampling area of $\sim 90 \mathrm{~m}^{2}$, while pooling 3 videos when visibility was $7 \mathrm{~m}$ resulted in a total sampling area of $\sim 103 \mathrm{~m}^{2}$.

Sample based rarefaction curves plotting the number of species against the number of UVC or videos sampled across the 3 sampling dates were calculated separately for each study site. Unconditional variance estimates were used to construct $95 \%$ confidence intervals for rarefaction curves (Colwell et al. 2012). Calculation of unconditional variance assumes that some species in the reference assemblage are not detected when all sampling units are pooled and, as recommended for sample-based data, Chao 2 was used as the estimator of asymptotic species richness (Colwell et al. 2012, Colwell 2013). At Site 1, UVC curves were extrapolated following the method proposed by Colwell et al. (2012), in order to allow the comparison with videos not biased by differences in total sampled area. Overlapping of confidence intervals, although a conservative criterion, was used to assess statistical significance of differences between UVC and video curves (Colwell et al. 2012). Analyses were run in EstimateS 9.1.0 (Colwell 2013).

Differences in the structure of fish assemblages between UVC and videos were analyzed by means of multivariate techniques. Variation in the whole assemblage was assessed by means of a 3-factor PERMANOVA (Anderson 2001), including the factors Technique (UVC versus video; fixed), Site (random and crossed with Technique) and Date (random and nested within the interaction Technique $\times$ Site), on Bray-Curtis dissimilarity calculated from either raw or presence/absence transformed data. The response of the analyses on dissimilarity measures calculated from untransformed data is largely influenced by the most abundant species, while that of analyses based on presence/absence data provides an insight into variations in composition and frequency of occurrence of species. The damselfish Chromis chromis, being ubiquitous and usually having an abundance an order of magnitude greater than the other species, was excluded from analyses since it would have had a disproportionate weight on their response. SIMPER was used to identify the species contributing most to differences between sampling techniques and taxa contributing at least $10 \%$ to dissimilarity were considered important differentiators. The density of the most common species, as well as species richness, was analysed by means of permutational ANOVAs (Anderson 2001), using the same design described for multivariate analyses. This technique allows unbalanced designs and, using permutations, distribution-free analyses. Multivariate and univariate analyses were performed using the software PERMANOVA+ for PRIMER (Anderson et al. 2008). Pooling procedures were used according to Winer et al. (1991) and relevant terms were eliminated when not significant at $\mathrm{p}=0.25$.

\section{Modelling species occupancy and detection probability from spearfishing videos}

Data from spearfishing videos recorded between August and November 2012 at 6 sites along the coast south of the city of Livorno (Fig. 1) were used to assess their potential for modelling species occupancy. The wrasse, Symphodus rostratus, was used as a model species, since, in contrast to most of the other species, it was not detected at all sampling sites. The occupancy of $S$. rostratus was modelled by following the approach proposed by Katsanevakis et al. (2011), which expands the single-season procedures developed by MacKenzie et al. $(2002,2006)$. In the general formulation by MacKenzie et al. (2002), the presence/absence of a species at a given number of $s$ sites is recorded $K$ times by the same or independent observers. In the approach proposed by Katsanevakis et al. (2011), and more recently applied by Issaris et al. (2012) and Salomidi et al. (2013), the replication of sampling through time is replaced by repeated independent observations by different observers. Detections by each single observers are considered as surveys sensu MacKenzie et al. (2006), generating, for each study site, a detection history consisting of a string of 1 (detection) and 0 (nondetection). In our case, each replicated video $(\mathrm{n}=11$ 
to 24) was considered as an independent survey and the detection history thereby generated was used to model species occupancy. Sampling inconsistencies can be managed using this procedure based on maximum likelihood (MacKenzie et al. 2002). Here, we report briefly on modeling procedures, as these have been described in full detail by previous papers (MacKenzie et al. 2002, Katsanevakis et al. 2011, Issaris et al. 2012, Salomidi et al. 2013). Species occupancy $\Psi$ was modelled jointly with detection probability $p_{\text {; }}$ a site can be scored as occupied, with probability $\Psi$, or as unoccupied, with probability $1-\Psi$, by the target species. If the species is present at the site, it can be detected by each of the $j$ surveys (i.e. video), with a probability $p_{j}$, or pass undetected, with a probability $q_{j}=1-p_{j}$. For example, having 4 surveys, the detection history $H_{i}=1000$ would indicate that the species was detected in the first survey only and its probability would be expressed as $\operatorname{Pr}\left(H_{i}\right)=\Psi p_{1} q_{2} q_{3}$ $q_{4}$. No detection of the model species by any of the surveys may indicate genuine absence or failure to detect it despite it being present and the probability of such detection history would be expressed as $\operatorname{Pr}\left(H_{i}\right)=\Psi q_{1} q_{2} q_{3} q_{4}+(1-\Psi)$. Assuming independent observations, the likelihood of the data is obtained by deriving these expressions for each of the observation histories generated across the $s$ sites sampled:

$$
L\left(\psi, \mathbf{p} \mid H_{1}, H_{2} \ldots, H_{s}\right)=\prod_{i=1}^{S} \operatorname{Pr}\left(H_{i}\right)
$$

where $\mathbf{p}$ represents the vector of detection probabilities.

Within this framework, covariates can be added in order to explain variability in either occupancy (i.e. site covariates), detection (i.e. survey covariates) or both (MacKenzie et al. 2002, Katsanevakis et al. 2011, Issaris et al. 2012). Covariates can be incorporated using the logistic model

$$
\theta_{i}=\exp \left(Y_{i} \boldsymbol{\beta}\right) \cdot\left(1+\exp \left(Y_{i} \boldsymbol{\beta}\right)\right)^{-1}
$$

where $\theta_{i}$ is the probability of either occupancy or detection, $Y_{i}$ are the covariates being modeled and $\boldsymbol{\beta}$ is the vector of covariate parameters to be estimated. Here, we included the standardized distance [(value - mean distance)/SD] from the commercial port of Livorno (one of the largest in the NW Mediterranean) as a site covariate, in order to test the alternative hypotheses that the occupancy of the model species ( $S$. rostratus) was constant across study sites (O1) or increasing with distance from the port, i.e. from more to less degraded sites (O2). In addition, we included video length and habitat features as survey covariates, testing the following detection assumptions: detection ability was constant across surveys (D1), varied among surveys according to video length, quantified as described in the previous paragraph (D2), or varied among surveys in relation to habitat features (D3). We identified 5 gross habitats according to dominant habitat formers or prevalent features of the substratum: (1) seagrass meadows (Posidonia oceanica); (2) assemblages composed by photophilic and/or turf-forming macroalgae; (3) coralligenous assemblages (a hard substratum of biogenic origin that is mainly produced by the accumulation of calcareous encrusting algae growing in dim light conditions); (4) mixed assemblages of (1) and (2); (5) mixed assemblages of (1) and (3). Combining the 2 assumptions for occupancy and the 3 for detectability generated 8 occupancy models (Table 3). Following an information-theoretic approach, the Akaike Information Criterion (AIC) was used to select the most plausible models. The best models among the candidates were identified according to $w$, the Akaike weight (Burnham \& Anderson 2002). The relative weight of predictor variables (i.e. the evidence in favour of the different hypotheses being tested) was estimated by summing up $w$ across the set of models in which each variable occurred (Burnham \& Anderson 2002). Model goodness of fit was assessed by means of chisquared statistic using the bootstrap procedure proposed by MacKenzie \& Bailey (2004). Finally, model averaged estimates of $\Psi$ and standard error were calculated from the set of the most plausible models following the procedures defined by Burnham \& Anderson (2002) and previously adopted in the context of species occupancy analyses in marine environments (e.g. Katsanevakis et al. 2011, Issaris et al. 2012). Analyses were run using the free software Presence v.3.1 (Hines 2006).

\section{RESULTS}

\section{Comparisons between spearfishing videos and UVC}

At both sites, 95\% confidence intervals of species accumulation curves overlapped throughout the entire sample size and thus there was no clear and strong evidence of differences between UVC and videos (Fig. 2). At Site 1, the 95\% confidence intervals of the video curve approaches zero (around the observed number of species), indicating that the accumulation of species had reached an asymptote (Fig. 2A). 


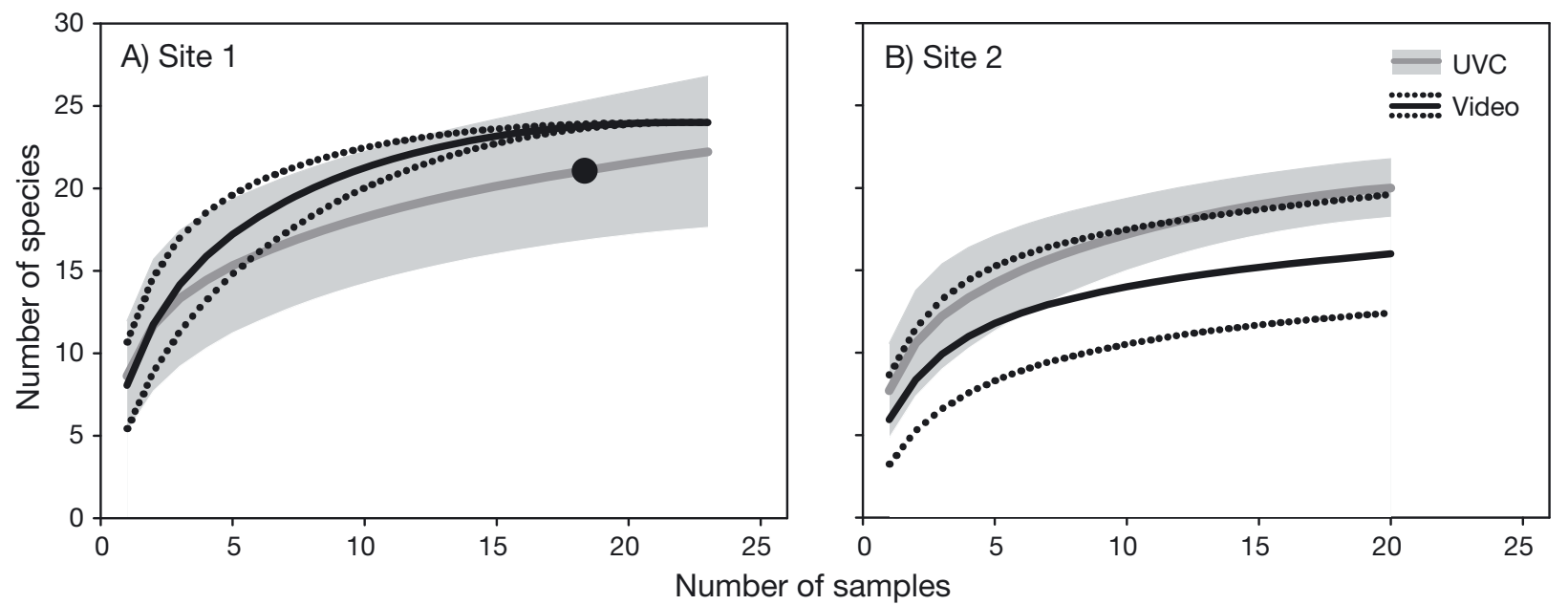

Fig. 2. Sample-based species accumulation curves and $95 \%$ unconditional variance confidence intervals for UVC and videos, separately for (A) Site 1 and (B) Site 2. The black dot super-imposed on the UVC curve in panel A marks the point separating the rarefaction and the extrapolation curve

Multivariate analyses on untransformed data detected significant differences between UVC and video in the structure of fish assemblages (Table 1). Few species contributed more than $10 \%$ of dissimilarity between sampling techniques (Table S2 in the Supplement); important differentiators between fish assemblages were Coris julis (36.95\%), Symphodus ocellatus (11.15\%) and Sarpa salpa $(10.14 \%)$. In contrast, there were no significant differences between UVC and video when analyses were performed on presence/absence data (Table 1). Variability among sampling dates was significant for analyses on both untransformed and presence/absence data (Table 1).

Five species were detected exclusively by UVC (Apogon imberbis, Boops boops, Sciaena umbra, Spicara maena, Spicara smaris) and 4 species by videos (Dentex dentex, Diplodus puntazzo, Sparus aurata and Thalassoma pavo) (Table S3 in the Supplement). The density of C. julis, Serranus cabrilla and Serranus scriba resulted greater in UVC than videos (Fig. 3, Table 2). In contrast, the density of the other species analyzed, as well as species richness, did not differ between the 2 sampling techniques (Table S4 in the Supplement).

\section{Modelling species occupancy and detection probability from spearfishing videos}

The best model ( $w=52.30 \%$ ) predicting the probability of presence of Symphodus rostratus was

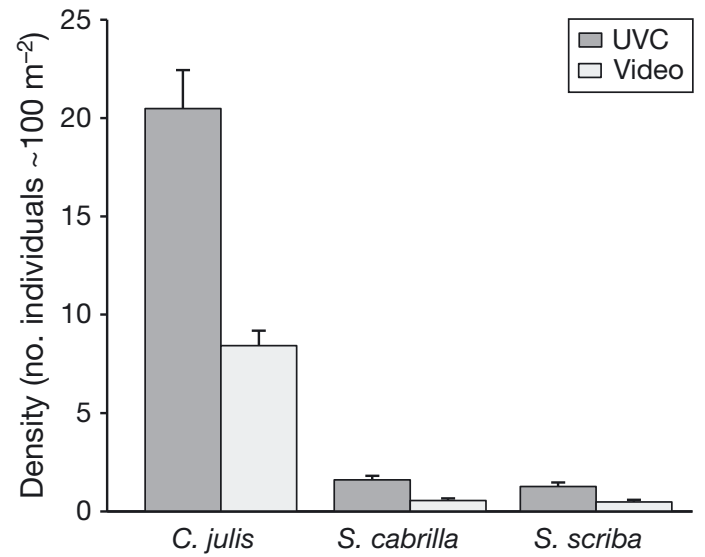

Fig. 3. Density (mean + SE) of Coris julis, Serranus cabrilla and Serranus scriba. Data are averaged across study sites and sampling times (UVC: $\mathrm{n}=43$; video: $\mathrm{n}=38$ )

$\Psi()$.$p (length), which supported assumptions \mathrm{O} 1$ and D2 (Table 3). There was no evidence of poor fit for this model (chi-squared test, $\mathrm{p}=0.25$ ). Two other models, $\Psi($ dist $) p($ length) and $\Psi() p.($.$) , were some-$ 
Table 2. PERMANOVA comparing the density of Coris julis, Serranus cabrilla and Serranus scriba between sites, sampling techniques (UVC versus video) and among dates. 999 permutations of the residuals were used for tests of significance. Degrees of freedom as in Table 1. Relevant terms were eliminated when not significant at $\mathrm{p}=0.25 .{ }^{*} \mathrm{p}<0.05 ;^{* *} \mathrm{p}<0.01$

\begin{tabular}{|c|c|c|c|c|c|c|}
\hline \multirow{2}{*}{$\begin{array}{l}\text { Source of } \\
\text { variation }\end{array}$} & \multicolumn{2}{|c|}{ C. julis } & \multicolumn{2}{|c|}{ - S. cabrilla - } & \multicolumn{2}{|c|}{ S. scriba } \\
\hline & MS & $F$ & MS & $F$ & MS & $F$ \\
\hline Site (S) & 215.510 & 0.80 & 0.010 & 0.04 & 0.658 & 0.74 \\
\hline Technique (T) & 2950.60 & $424.71^{*}$ & 19.484 & $8.66^{*}$ & 12.500 & $14.11^{* *}$ \\
\hline $\mathrm{S} \times \mathrm{T}$ & 6.950 & 0.03 & eliminated & & eliminated & \\
\hline Date $(\mathrm{S} \times \mathrm{T})$ & 276.520 & 5.13 & 2.306 & 2.79 & 0.881 & 0.87 \\
\hline Residual & 53.890 & & 0.826 & & 1.016 & \\
\hline
\end{tabular}

Table 3. Set of candidate models predicting the probability of presence ( $\Psi)$ of Symphodus rostratus in the study area, using simple logistic regression. Reported values are twice the negative likelihood $(-21)$, the number of parameters included in the model $(K)$, the relative difference from the Akaike's information criterion (AIC) value of the top-ranked model $(\triangle \mathrm{AIC})$ and the AIC model weight $(w)$ expressed as a percentage. $()=$. constant occupancy or constant detection; dist $=$ distance from the port; length $=$ video length; habitat = habitat features

\begin{tabular}{|lrrrr|}
\hline Model & -21 & $K$ & $\Delta$ AIC & $w(\%)$ \\
\hline$\Psi() p.($ length $)$ & 35.12 & 3 & 0.00 & 52.30 \\
$\Psi($ dist $) p($ length $)$ & 35.12 & 4 & 2.00 & 19.24 \\
$\Psi() p.()$. & 39.20 & 2 & 2.08 & 18.49 \\
$\Psi($ dist $) p()$. & 39.20 & 3 & 4.08 & 6.80 \\
$\Psi() p.($ length + habitat) & 32.12 & 8 & 7.00 & 1.58 \\
$\Psi() p.($ habitat $)$ & 35.63 & 7 & 8.51 & 0.74 \\
$\Psi($ dist $) p($ length + habitat $)$ & 32.12 & 9 & 9.00 & 0.58 \\
$\Psi($ dist $p$ (habitat) & 35.63 & 8 & 10.51 & 0.27 \\
\hline
\end{tabular}

what supported by the data. Overall, there was substantial support for the assumption of constant occupancy by $S$. rostratus across sites $\left[w_{+}(\mathrm{O} 1)=73.11 \%\right.$ ] and for that of detectability to be related to video length $\left[w_{+}(\mathrm{D} 2)=73.70 \%\right]$, but not to habitat features $\left[w_{+}(\mathrm{D} 3)=3.17 \%\right]$. The detectability of $S$. rostratus increased with video length as shown by the positive coefficient associated to this variable in all models including it. Based on the best model, detectability varied between 0.002 and 0.493 . Based on averagemodel estimates (4 best models in Table 3), the occupancy of $S$. rostratus in the study area was $0.941 \pm$ 0.164 (mean $\pm \mathrm{SE})$.

\section{DISCUSSION}

Videos recorded by recreational, breath-holding spearfishers provided estimates of species richness comparable to those obtained from strip transects, a common UVC technique. These results are somewhat in contrast with some studies (also carried out in the Mediterranean) reporting generally lower estimates of species richness obtained via remotely operated videos compared to strip transects (Francour et al. 1999, Stobart et al. 2007, Pelletier et al. 2011). In virtue of their greater perimeter-toarea ratio, strip transects are likely to sample a wider range of habitats than point recordings, such as those produced by remotely operated videos, and they are therefore more likely to detect more benthic and pelagic species (Francour et al. 1999, Stobart et al. 2007). No different from stationary point counts (Bohnsack \& Bannerot 1986), one spearfishing video is unlikely to sample multiple habitats, with its detection power varying with habitat complexity. Nonetheless, the relatively large number of dives during a spearfishing session (in total, 62 at Site 1 and 52 at Site 2) was likely as effective as transects in sampling the diversity of habitats at our study sites and, hence, in detecting species. We emphasize that the number of dives during each of the experimental fishing sessions is well within the range of dives that a spearfisher with average training performs in a 2 to $3 \mathrm{~h}$ session (F. Bulleri pers. obs.).

As shown by the worked example on Symphodus rostratus, estimates of species occupancy and species richness from spearfishing videos can be enhanced by using procedures for taking into account imperfect detectability (MacKenzie et al. 2002, 2006, Katsanevakis et al. 2011, Issaris et al. 2012). Unfortunately, sampling with both techniques was performed at only 2 sites and, within each of them, sampled units (either transects or video) were not fixed but changed from one time of sampling to another, preventing assignation of detection history. Thus, it was not possible to formally compare estimates of species occupancy and detection probability between the 2 techniques. Nonetheless, our modeling, despite including a relatively small number of sites, shows how a probability of occupancy can be assigned to fish species ( $S$. rostratus, in this case) also at sites in which it has not been recorded.

An important point is that both occupancy and detection probability can be modelled as a function of important environmental and technical covariates (see Katsanevakis et al. 2011, Issaris et al. 2012, Salomidi et al. 2013 for marine examples). For instance, 
as emerged for $S$. rostratus, footage length, which is highly variable among spearfishing videos, is likely to have an important bias on detection probability. Addressing such bias seems, however, straightforward. Likewise, the effects of a spearfisher selecting particular habitat patches on rocky reefs on estimates of species occupancy may be accounted for by treating habitat features (extractable from each video) as a detection covariate. In addition, habitat features might be used to improve occupancy estimates when study sites markedly differ in their regard. Finally, although models including the distance from the port as an occupancy probability covariate received little support in the case of $S$. rostratus, our analyses show that spearfishing videos might provide useful data for testing hypotheses regarding variations in species distributions as a consequence of human or natural variation in environmental conditions at regional scales (Katsanevakis et al. 2011, Issaris et al. 2012, Salomidi et al. 2013). Importantly, these analyses should be applied with caution to highly mobile fish species since sites are assumed to be closed (i.e. occupancy remains constant) over the sampling period (MacKenzie et al. 2002, 2006).

The actual area sampled by any visual technique is likely larger or smaller than that in which counts are performed and varies among species. Fish species will be attracted/repelled to a different extent by the presence of either a SCUBA diver, a baited or an unbaited camera; spearfishing videos are no exception, since some species are generally attracted by the presence of the spearfisher on the bottom (which is why the sit-and-wait technique is used), while others are not. However, this does not represent a major hurdle when the data extracted from spearfishing videos are used to run spatial or temporal comparisons (and not used to estimate absolute abundances).

High levels of disturbance can promote a reaction to flee in fish (Kulbicki 1998, Cinner et al. 2006, Guidetti et al. 2008, Januchowski-Hartley et al. 2013), ultimately biasing UVC surveys (Feary et al. 2011). In disturbed areas, species that are naturally shy or have increased wariness through learning are often detected by SCUBA divers at the limit of the transect belt or spotted outside of the sampling area and are therefore not included in species counts (HarmelinVivien et al. 1985, F. Bulleri pers. obs.) Only fixed, remotely operated video recorders have been, therefore, envisioned as a valid tool to record shy species (Francour et al.1999). Although Cole et al. (2007) did not detect major advantages of sampling fish assemblages using re-breathers, filming by spearfishers holding their breath and hiding on the bottom may minimize some of the biases due to the presence of a SCUBA diver, such as noise and bubbles, and enhance the detection of species that exhibit a shy behaviour in disturbed areas.

For instance, the presence of relatively uncommon predators, such as Dentex dentex and Sparus aurata (medium-sized individuals), was detected only by videos. Thus, detectability of some shy species may be greater using sit-and-wait spearfishing videos than SCUBA divers, at least in fished areas. Such an advantage of spearfishing videos may lessen in MPAs, where fish are used to and can be indeed attracted by the presence of SCUBA divers (e.g. food association; Cole 1994, Milazzo et al. 2005). On the other hand, spearfishing videos recorded while using the sit-and-wait technique are likely to underestimate the abundance of sedentary species. This fishing technique is only occasionally effective for approaching the dusky grouper Epinephelus marginatus, the meagre Sciaena umbra, the rock cod Scorpaena scrofa, the European conger Conger conger and the moray eel Muraena helena - species characterized by a high site fidelity and/or a shy habit in fished areas (S. Bellani pers. comm.).

Multivariate analyses on presence/absence data did not reveal significant differences in the species composition of fish assemblages between UVC and videos. In contrast, differences emerged when analyses were run on raw data. Few species contributed to multivariate patterns and the relative abundance of a small subset of these differed significantly between UVC and videos. Estimates of the density of the combers, Serranus cabrilla and Serranus scriba and that of the Mediterranean rainbow wrasse, Coris julis, were greater in UVC than videos.

For BRUVS, species-specific response to the bait has been shown to affect the relationship between deployment time and species detectability or relative abundance (Willis \& Babcock 2000, Yau et al. 2001, Stobart et al. 2007). Spearfishing videos are orders of magnitude shorter than ad hoc stationary remotely operated videos (e.g. lasting 10s of minutes). Nonetheless, there was no significant correlation between recording time and relative abundance $(\operatorname{Max} N)$ for any of the species detected. C. julis, S. cabrilla and $S$. scriba are not shy species, but they tend to approach the spearfisher (or the BRUV; Stobart et al. 2007) as soon as it reaches the bottom (F. Bulleri pers. obs.). Thus, the tendency of these species to approach and follow the diver while sampling strip transects may explain larger estimates of their densities in respect to videos. 
Our results suggest that spearfishing videos might be a valuable source of information on the structure of fish assemblages on shallow rocky reefs. The greatest strength of spearfishing videos as a sampling tool lies in their availability: a simple YouTube search for spearfishing resulted in 2900000 hits (performed on the 4 November 2013). Of course, these numbers include videos that are only marginally related to spearfishing or recorded using fishing techniques other than sit-and-wait and they are, therefore, unlikely to provide quantitative estimates of species richness and relative abundances. On the other hand, these videos generally report noteworthy catches or fishing action and, hence, are only a small proportion of the bulk recorded but not shared within the broad spearfisher community. Spearfishing is very popular along the coasts of the Mediterranean (Lloret et al. 2008) and we argue that opening a basin-wide call for videos may allow assessing variation in the structure of shallow fish assemblages at spatial and temporal scales that are well beyond those allowed by ad hoc sampling campaigns operated by scientific divers. However, we stress that this does not imply that spearfishing videos represent a solution to the variety of biases that have been identified for visual sampling techniques (HarmelinVivien et al. 1985, Willis \& Babcock 2000, Cappo et al. 2004, Edgar et al. 2004, Cole et al. 2007, Stobart et al. 2007, Tessier et al. 2013).

Along with the possibility of archiving, one of the main advantages of videos over UVC is that of eliminating the bias due to variability among observers. In this case, spearfishers have no role in data extraction from videos, eliminating some of the most serious biases that affect citizen science (e.g. variation in experience, ability, and/or training; Dickinson et al. 2010). Biases introduced by variations in fishing skills and behavior among spearfishers could be formally assessed following the modeling approach used in this study whether the same site/s is repeatedly sampled by different spearfishers. Thus, estimates of the viewing angle of the videocamera and of visibility, key for obtaining estimates of the surface sampled, might be a major hurdle for the use of videos. Likewise, the accuracy of geo-referencing the information from videos would be entirely dependent upon the fidelity of the information provided by spearfishers. Finally, the possibility of extracting representative estimates of fish species richness and relative abundances, as well as of measures of variability, relies on the will of spearfishers to provide all or most (i.e. a random sample) of the videos recorded during a fishing session, irrespective of catching success.
Importantly, information extracted from videos is not limited to native components of resident assemblages, but extends to non-indigenous species. Several Indo-Pacific fish species have established in the Levantine Basin (Edelist et al. 2013) and spearfishing videos could be used to monitor their expansion throughout the Mediterranean. Likewise, they could be useful to track northward expansions of long naturalized species (e.g. Thalassoma pavo) as a consequence of seawater warming. In addition, the presence of non-indigenous sessile benthic species can be revealed and their frequency of occurrence quantified from spearfishing videos. For example, at our study sites, the invasive macroalgae, Caulerpa racemosa and Asparagopsis taxiformis, were observed in several videos.

In contrast to most studies attempting to assess the validity of remotely or diver operated video as a sampling technique, generally carried out in MPAs (Willis et al. 2000, Willis \& Babcock 2000, Stobart et al. 2007, Tessier et al. 2013), this study was carried out along a coast characterized by heavy exploitation of fish assemblages by both commercial and recreational fisheries. On the one hand, this has prevented an assessment of how the effectiveness of spearfishing videos in sampling large predatory fish (rare at our study sites) compares to that of traditional UVC. On the other hand, it has allowed us to establish that spearfishing videos represent a promising tool for sampling fish assemblages in exploited areas, where videos are more likely to be contributed by recreational spearfishers. Spearfishing videos may thus also provide a unique opportunity to enhance our knowledge of the structure of fish assemblages along human-dominated coasts (a vast proportion of coastlines of developed countries), and, hence, set the stage for conservation and restoration efforts where they are more needed (Miller \& Hobbs 2002).

Acknowledgements. We sincerely thank F. Bertocci, M. Martini, D. Sircana and E. Torrini for their support during the project and M. Dal Bello and 3 anonymous reviewers for commenting on an earlier version of the manuscript. This work benefitted from funds from the MIUR through the PRIN 2010 project TETRIS.

\section{LITERATURE CITED}

Anderson MJ (2001) A new method for non-parametric multivariate analysis of variance. Austral Ecol 26:32-46

Anderson MJ, Gorley RN, Clarke KR (2008) PERMANOVA+ for PRIMER. Guide to Software and Statistical Methods. PRIMER-E, Plymouth

Bohnsack SA, Bannerot SP (1986) A stationary visual census technique for quantitatively assessing community struc- 
ture of coral reef fishes. NOAA Tech Rep NMFS 41

Bramanti L, Vielmini I, Rossi S, Stolfa S, Santangelo G (2011) Involvement of recreational scuba divers in emblematic species monitoring: the case of Mediterranean red coral (Corallium rubrum). J Nat Conserv 19:312-318

Burnham KP, Anderson DR (2002) Model selection and multimodal inference, 2nd edn. Springer-Verlag, New York, NY

Cappo M, Speare P, De'ath G (2004) Comparison of baited remote underwater video stations (BRUVS) and prawn (shrimp) trawls for assessments of fish biodiversity in inter-reefal areas of the Great Barrier Reef Marine Park. J Exp Mar Biol Ecol 302:123-152

Cinner J, Marnane MJ, McClanahan TR, Almany GR (2006) Periodic closures as adaptive coral reef management in the Indo-Pacific. Ecol Soc 11:31, www.ecologyandsociety. org/vol11/iss1/art31/

> Cole RG (1994) Abundance, size structure, and diveroriented behavior of 3 large benthic carnivorous fishes in a marine reserve in northeastern New Zealand. Biol Conserv 70:93-99

Cole RG, Syms C, Davey NK, Gust N and others (2007) Does breathing apparatus affect fish counts and observations? A comparison at three New Zealand fished and protected areas. Mar Biol 150:1379-1395

Colton MA, Swearer SE (2010) A comparison of two survey methods: differences between underwater visual census and baited remote underwater video. Mar Ecol Prog Ser 400:19-36

Colwell RK (2013) EstimateS v.9: Statistical estimation of species richness and shared species from samples. http://purl.oclc.org/estimates

> Colwell RK, Chao A, Gotelli NJ, Lin SY, Xuan Mao C, Chazdon RL, Longino JT (2012) Models and estimators linking individual-based and sample-based rarefaction, extrapolation and comparison of assemblages. J Plant Ecol 5:3-21

> Delaney DG, Sperling CD, Adams CS, Leung B (2008) Marine invasive species: validation of citizen science and implications for national monitoring networks. Biol Invasions 10:117-128

> Dickinson JL, Zuckerberg B, Bonter DN (2010) Citizen science as an ecological research tool: challenges and benefits. Annu Rev Ecol Evol Syst 41:149-172

Edelist D, Rilov G, Golani D, Carlton JT, Spanier E (2013) Restructuring the sea: profound shifts in the world's most invaded marine ecosystem. Divers Distrib 19:69-77

Edgar GJ, Barrett NS, Morton AJ (2004) Biases associated with the use of underwater visual census techniques to quantify the density and size-structure of fish populations. J Exp Mar Biol Ecol 308:269-290

Ellis DM, DeMartini EE (1995) Evaluation of a video camera technique for indexing abundances of juvenile pink snapper, Pristipomoides filamentosus, and other Hawaiian insular shelf fishes. Fish Bull 93:67-77

> Feary DA, Cinner JE, Graham NAJ, Januchowski-Hartley FA (2011) Effects of customary marine closures on fish behavior, spear-fishing success, and underwater visual surveys. Conserv Biol 25:341-349

> Francisco-Ramos V, Arias-González JE (2013) Additive partitioning of coral reef fish diversity across hierarchical spatial scales throughout the Caribbean. PLoS ONE 8:e78761

Francour P, Liret C, Harvey E (1999) Comparison of fish abundance estimates made by remote underwater video and visual census. Nat Sicil 23:155-168

Goffredo S, Piccinetti C, Zaccanti F (2004) Volunteers in marine conservation monitoring: a study of the distribution of seahorses carried out in collaboration with recreational scuba divers. Conserv Biol 18:1492-1503

Guidetti P (2006) Marine reserves reestablish lost predatory interactions and cause community changes in rocky reefs. Ecol Appl 16:963-976

- Guidetti P, Vierucci E, Bussotti S (2008) Differences in escape response of fish in protected and fished Mediterranean rocky reefs. J Mar Biol Assoc UK 88:625-627

Harmelin-Vivien ML, Harmelin JG, Chauvet C, Duval C and others (1985) The underwater observation of fish communities and fish populations - methods and problems. Rev Ecol Terre Vie 40:466-539

Heagney EC, Lynch TP, Babcock RC, Suthers IM (2007) Pelagic fish assemblages assessed using mid-water baited video: standardising fish counts using bait plume size. Mar Ecol Prog Ser 350:255-266

Hines JE (2006) PRESENCE 2 - Software to estimate patch occupancy and related parameters. www.mbr-pwrc. usgs.gov/software/presence.html (accessed February 2014)

Issaris Y, Katsanevakis S, Salomidi M, Tsiamis K, Katsiaras N, Verriopoulos G (2012) Occupancy estimation of marine species: dealing with imperfect detectability. Mar Ecol Prog Ser 453:95-106

> Januchowski-Hartley FA, Graham NAJ, Cinner JE, Russ GR (2013) Spillover of fish naïveté from marine reserves. Ecol Lett 16:191-197

Katsanevakis S, Zenetos A, Ma i V, Beqiraj S, Poursanidis D, Kashta L (2011) Invading the Adriatic: spatial patterns of marine alien species across the Ionian-Adriatic boundary. Aquat Biol 13:107-118

Kulbicki M (1998) How the acquired behaviour of commercial reef fishes may influence the results obtained from visual censuses. J Exp Mar Biol Ecol 222:11-30

> Lloret J, Zaragoza N, Caballero D, Font T, Casadevall M, Riera V (2008) Spearfishing pressure on fish communities in rocky coastal habitats in a Mediterranean marine protected area. Fish Res 94:84-91

MacKenzie DI, Bailey LL (2004) Assessing the fit of site occupancy models. J Agric Biol Environ Stat 9:300-318

MacKenzie DI, Nichols JD, Lachman GB, Droege S, Royle JA, Langtimm CA (2002) Estimating site occupancy rates when detection probabilities are less than one. Ecology 83:2248-2255

MacKenzie DI, Nichols JD, Royle JA, Pollock KH, Bailey LL, Hines JE (2006) Occupancy estimation and modeling. Academic Press, San Diego, CA

> Milazzo M, Badalamenti F, Fernandez TV, Chemello R (2005) Effects of fish feeding by snorkellers on the density and size distribution of fishes in a Mediterranean marine protected area. Mar Biol 146:1213-1222

> Miller JR, Hobbs RJ (2002) Conservation where people live and work. Conserv Biol 16:330-337

Pelletier D, Leleu K, Mou-Tham G, Guillemot N, Chabanet P (2011) Comparison of visual census and high definition video transects for monitoring coral reef fish assemblages. Fish Res 107:84-93

> Priede IG, Merrett NR (1998) The relationship between numbers of fish attracted to baited cameras and population density: studies on demersal grenadiers Coryphaenoides (Nematonurus) armatus in the abyssal NE Atlantic Ocean. Fish Res 36:133-137 
Priede IG, Bagley PM, Smith KL (1994) Seasonal change in activity of abyssal demersal scavenging grenadiers Coryphaenoides (Nematonurus) armatus in the eastern North Pacific Ocean. Limnol Oceanogr 39:279-285

Rosevelt C, Los Huertos M, Garza C, Nevins HM (2013) Marine debris in central California: quantifying type and abundance of beach litter in Monterey Bay, CA. Mar Pollut Bull 71:299-306

Salomidi M, Katsanevakis S, Issaris Y, Tsiamis K, Katsiaras $N$ (2013) Anthropogenic disturbance of coastal habitats promotes the spread of the introduced scleractinian coral Oculina patagonica in the Mediterranean Sea. Biol Invasions 15:1961-1971

Stobart B, García-Charton JA, Espejo C, Rochel E, and others (2007) A baited underwater video technique to assess shallow-water Mediterranean fish assemblages: methodological evaluation. J Exp Mar Biol Ecol 345:158-174

Tamburello L, Benedetti-Cecchi L, Ghedini G, Alestra T, Bulleri F (2012) Variation in the structure of subtidal landscapes in the NW Mediterranean Sea. Mar Ecol Prog Ser 457:29-41

Tessier A, Pastor J, Francour P, Saragoni G, Crec'hriou R, Lenfant P (2013) Video transects as a complement to underwater visual census to study reserve effect on fish assemblages. Aquat Biol 18:229-241

Vitousek PM, Mooney HA, Lubchenco J, Melillo JM (1997)

Editorial responsibility: Stylianos Somarakis, Heraklion, Greece
Human domination of Earth's ecosystems. Science 277:494-499

Ward-Paige CA, Lotze HK (2011a) Assessing the value of recreational divers for censusing elasmobranchs. PLoS ONE 6:e25609

Ward-Paige CA, Pattengill-Semmens C, Myers RA, Lotze HK (2011b) Spatial and temporal trends in yellow stingray abundance: evidence from diver surveys. Environ Biol Fishes 90:263-276

Willis TJ, Babcock RC (2000) A baited underwater video system for the determination of relative density of carnivorous reef fish. Mar Freshw Res 51:755-763

- Willis TJ, Millar RB, Babcock RC (2000) Detection of spatial variability in relative density of fishes: comparison of visual census, angling, and baited underwater video. Mar Ecol Prog Ser 198:249-260

Winer BJ, Brown DR, Michels KM (1991) Statistical principles in experimental design. McGraw-Hill, New York, NY

Witt MJ, Hardy T, Johnson L, McClellan CM, Pikesley SK, Ranger S, and others (2012) Basking sharks in the northeast Atlantic: spatio-temporal trends from sightings in UK waters. Mar Ecol Prog Ser 459:121-134

Yau C, Collins MA, Bagley PM, Everson I, Priede IG (2001) Estimating the abundance of Patagonian toothfish Dissostichus eleginoides using baited cameras: a preliminary study. Fish Res 51:403-412

Submitted: November 19, 2013; Accepted: April 1, 2014 Proofs received from author(s): June 10, 2014 